\title{
A DESCRIPTIVE STUDY ON THE CLINICAL MANIFESTATIONS AND SEVERITY OF PSORIASIS IN PATIENTS PRESENTING TO DERMATOLOGY OPD OF A TERTIARY HEALTH CARE CENTER IN CENTRAL KERALA
}

Arathy Jayakumar ${ }^{1}$, Seena $P^{2}$

${ }_{1}^{1}$ Final Year MBBS Student, Government Medical College, Kottayam, Kerala, India.

${ }^{2}$ Associate Professor, Department of Dermatology, Government Medical College, Kottayam, Kerala, India.

\section{BACKGROUND}

ABSTRACT

Psoriasis is heterogeneous in its history, manifestations, presenting age, sites affected and environmental triggers. It presents as small localized lesions to generalized exfoliation type. An understanding of the most common clinical manifestation and degree of severity will help improve the standards of treatment and in turn improve the quality of life of psoriatic patients. Only very few studies have gone through this. The aim is to study the different clinical manifestations, aggravating factors, severity and most common presentations among the psoriasis patients presenting to the Dermatology OPD of Government Medical College, Kottayam.

\section{MATERIALS AND METHODS}

This is a descriptive study conducted over a period of two months in the Department of Dermatology and Venereology, Government Medical College. The study was conducted with a semi-structured interview schedule recording history, examination, PASI score and diagnosis. The data so obtained was entered in Microsoft Excel and analyzed using SPSS software.

\section{RESULTS}

$30.5 \%$ of the study sample had a history of aggravation of disease with seasonal variations (Summer) and $25.6 \%$ showed multifactorial aggravation. $17.1 \%$ had a family history of psoriasis. $87.8 \%$ had localized lesions. $92.7 \%$ presented with plaques. The most common type was chronic plaque (36.6\%). As per PASI, 56\% had mild, $22 \%$ each had moderate and severe psoriasis.

\section{CONCLUSION}

Chronic plaque psoriasis is the most common clinical type and most people present at the mild stage of the disease. Moderate and severe forms can be reduced by avoiding the aggravating factors. Planning appropriate treatment can significantly improve the quality of life of psoriasis patients.

\section{KEY WORDS}

Psoriasis, PASI, Arthritis.

HOW TO CITE THIS ARTICLE: Jayakumar A, Seena P. A descriptive study on the clinical manifestations and severity of psoriasis in patients presenting to dermatology OPD of a tertiary health care center in central Kerala. J. Evolution Med. Dent. Sci. 2018;7(52): 5555-5559, DOI: $10.14260 /$ jemds/2018/1229

\section{BACKGROUND}

Psoriasis is, of no doubt, a dermatological entity, but its effects are much deeper than skin. It has a prevalence of 0.6$4.8 \%$ around the world. ${ }^{1}$ Due to the association with several other diseases and concurrent illnesses, called comorbidities, psoriasis is considered as a systemic disease. ${ }^{2}$ Psoriasis patients have a higher prevalence of metabolic syndromes as well as its individual components (Diabetes mellitus, abdominal obesity, dyslipidaemia, hypertension ${ }^{3}$ ) when compared to general population ${ }^{4}$ and the prevalence increases with severity and duration. ${ }^{5}$ The complex aetiology of the disease includes both genetic and environmental factors like trauma [Koebner's phenomenon], seasonal variations [Winter], UV light, infections (Caused by haemolytic

'Financial or Other Competing Interest': None.

Submission 16-11-2018, Peer Review 11-12-2018,

Acceptance 17-12-2018, Published 24-12-2018.

Corresponding Author:

Dr. Seena P

Associate Professor,

Department of Dermatology,

Government Medical College,

Kottayam, Kerala, India.

E-mail: drseenapalakkal@gmail.com

DOI: $10.14260 /$ jemds/2018/1229

\section{(c) $($ ) $\$$}

streptococci), drugs [NSAIDs, $\beta$-blockers, $\mathrm{Li}$ salts, antimalarials], stress, alcohol, smoking and HIV and dietary factors. ${ }^{6,7}$

Rapid epidermal proliferation and dermal capillary derangements occur in psoriasis. ${ }^{8}$ The classical lesions are well circumscribed, itchy, salmon pink papules/plaques with silver white loosely adherent dry scales. ${ }^{9}$ The most common sites involved are the elbows, knees, scalp, lumbo-sacral skin, palms and soles. ${ }^{10}$ The most common site of involvement are palms according to a hospital based study conducted in four zones of India. ${ }^{11}$ Yellowish discolouration and onycholysis of the nail at the free/lateral edges may also be seen along with subungual hyperkeratosis, thickening or grooving of the nail. ${ }^{12}$ Psoriatic arthritis is a multigenic autoimmune disease that involves synovial tissue, enthesial sites and skin, that may result in significant joint damage. ${ }^{13,14}$

The different types are Chronic plaque psoriasis/ Psoriasis vulgaris (90\% of total cases), Inverse/Flexural/ Sebopsoriasis, Guttate psoriasis (Drop shaped), Palmar and Plantar psoriasis, ${ }^{15}$ Nail psoriasis, Rupioid, Elephantine and Ostraceous psoriasis, Pustular psoriasis, Exfoliative/ Erythrodermic psoriasis, ${ }^{16}$ Psoriatic Arthritis. Psoriasis Area Severity Index (PASI) is the gold standard for assessing extensive psoriasis and its response to any therapeutic Regimen. ${ }^{17}$ 
- $\quad$ PASI ranges from 0-72.

- $\quad$ PASI $<7--\rightarrow$ mild

- PASI 7-15-- $\rightarrow$ moderate

- $\quad$ PASI $>15--\rightarrow$ severe $^{18}$

Psoriasis patients are more prone to anxiety, depression and stress. ${ }^{19,20}$ Because of the contrasting results obtained from previous studies and the paucity of data from the state, our aim was to arrive at a more consistent result and fill the gap in the existing knowledge regarding the clinical profile of psoriasis. Descriptive study design has been selected to effectively explain the dermatological variants and severity patterns of psoriasis.

\section{MATERIALS AND METHODS \\ Study Design}

This was a descriptive study conducted in the outpatient of Department of Dermatology and Venereology, Government Medical College, Kottayam from May 2017 to June 2017, including clinically diagnosed psoriasis patients. The sample size for the study was calculated as 82 .

\section{Data Collection}

After obtaining IRB clearance, a semi-structured interview questionnaire was prepared. Consecutive patients were selected while we excluded the ones on immunosuppressant therapy. Consent was taken and a detailed history was taken. Dermatological examination was done to find out the site, extend, morphology, borders, erythema, scaling, induration and distribution of the lesions. Severity was assessed according to the modified PASI scoring. Koebner's phenomenon, Auspitz sign, joint, nail and mucosal involvement were separately examined.

\section{Statistical Analysis}

The data so obtained was entered in Microsoft Excel and analysed using SPSS version 16.0. The frequencies and percentages were obtained for different variables. The relation between severity and different variables were analysed by forming cross tabs taking the chi-square test.

\section{RESULTS}

Majority of the study sample (46.3\%) belonged to the age group $41-60$ and $59.8 \%$ of them were males. $56.1 \%$ developed the disease after the age of 40 and $34.1 \%$ developed the disease between 12 and 40 years of age. Only $9.8 \%$ of them developed the disease before the age of 12 .

In $30.5 \%$ seasonal variations aggravated the condition, while $26.8 \%$ of the patients did not report any aggravating factors. $25.6 \%$ showed multiple aggravating factors which means combinations of seasonal variations, trauma, diet, smoking, alcohol, drugs or pregnancy.

Only $17.1 \%$ had a history of similar illness in the family.

Lesions were localized in $87.8 \%$ and $12.2 \%$ had generalized lesions. $92.7 \%$ of the participants had plaques, $3.7 \%$ had macules, $2.4 \%$ had pustules and the rest had papules. $52.4 \%$ had lesions with ill-defined borders and $47.6 \%$ had well-defined borders.

The majority of people had lesions on head (Scalp or face) 42.7\%, while $32.9 \%$ had lower limb lesions, $17.1 \%$ had trunk involvement and only $7.3 \%$ had lesions on the upper limbs.
$12.2 \%$ had axillary lesions, $19.5 \%$ had lesions on the palms, $26.8 \%$ had lesions on the soles and $28 \%$ had lesions on their nails. None of the participants of the study presented with oral mucosal lesions while $2.4 \%$ participants had lesions on their genitalia. $22 \%$ of the study sample had joint involvement (Psoriatic arthritis).

\section{Types of Psoriasis}

$36.6 \%$ had Psoriasis vulgaris and $19.5 \%$ presented with nail psoriasis. 9.8\% had plantar psoriasis, $4.9 \%$ had palmoplantar psoriasis and $2.4 \%$ had palmar psoriasis. $3.7 \%$ had pustular psoriasis and $1.2 \%$ had erythrodermic psoriasis.

\section{Severity of Psoriasis as per PASI}

$56 \%(46 / 82)$ presented with mild psoriasis while $22 \%$ had moderate psoriasis and $22 \%$ presented with severe psoriasis. Head involvement (Scalp and face) predominated in mild disease (71.7\%). Lower limb involvement is higher in both moderate and severe forms with $50 \%$ and $94.4 \%$ respectively. The difference in proportion of disease severity among different sites [trunk, head, upper limbs and lower limbs] is statistically significant with a Pearson chi-square value of 63.200 and a p value of 0.000 .

\section{Association of Severity and Joint Involvement}

In severe form, $50 \%$ had joint involvement. This was statistically significant with a Pearson chi-square value of 10.689 and a $p$ value of 0.005 .

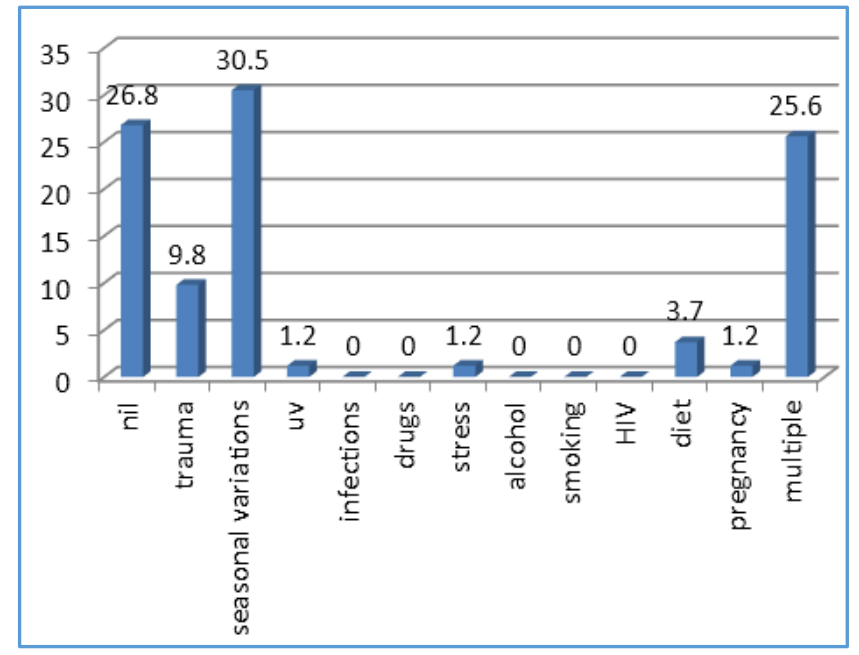

Table 1. Distribution of Different Aggravating Factors among the Study Population

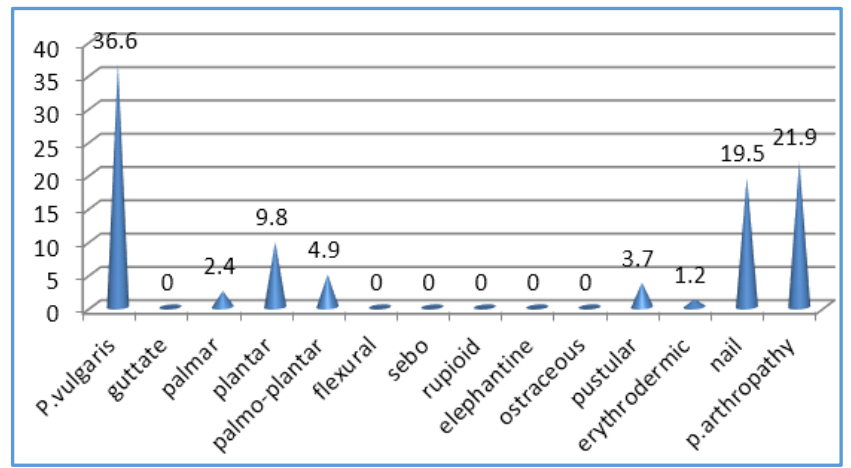

Table 2. Distribution of Different Morphological Types of Psoriasis among the Study Population 


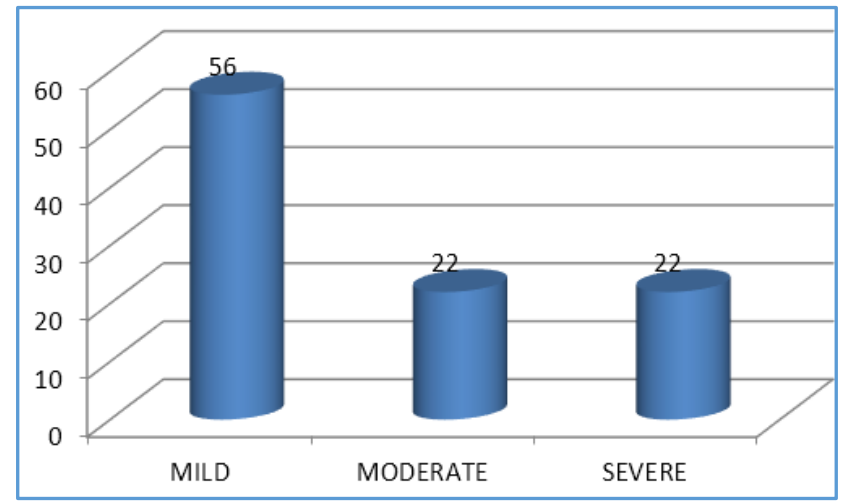

Table 3. Distribution of Study Sample according to the Severity of Disease

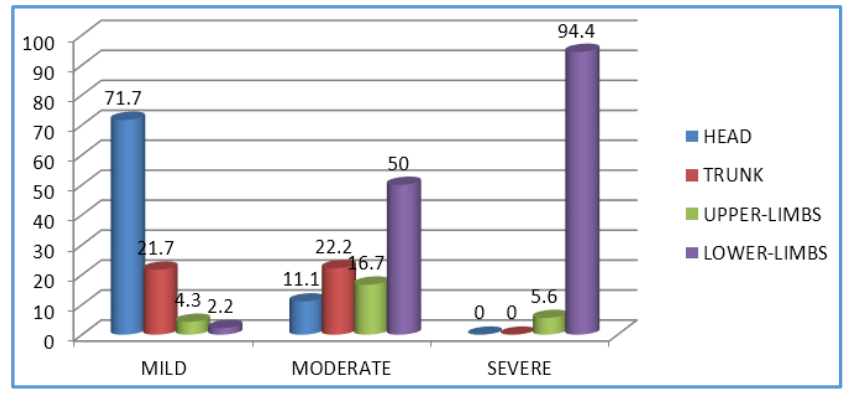

Table 4. Distribution of Severity of Lesions according to Site of Lesions

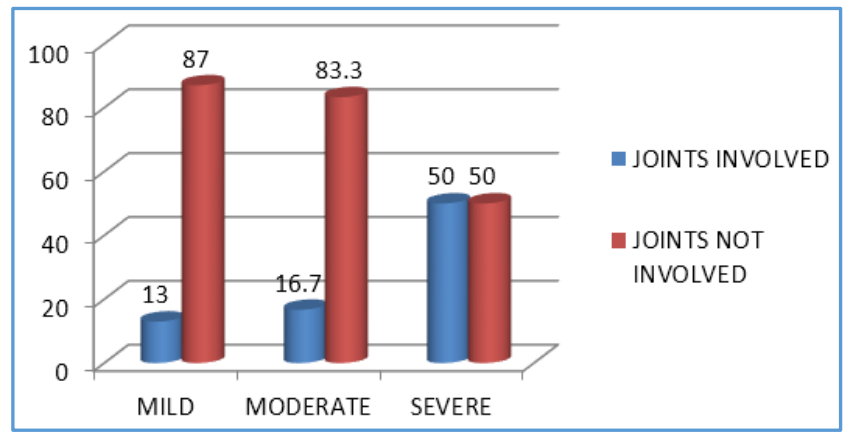

Table 5. Distribution of Involvement of Joints and Severity

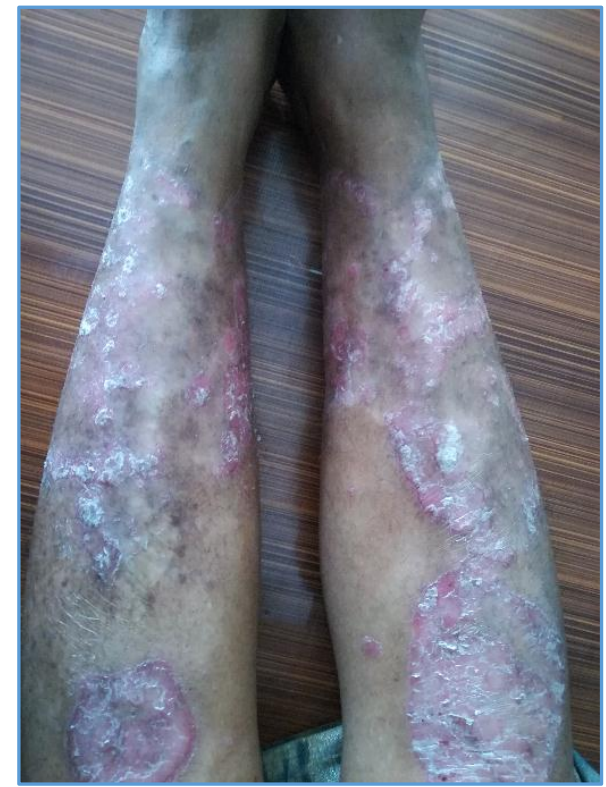

Figure 1. Clinical Picture of Psoriasis

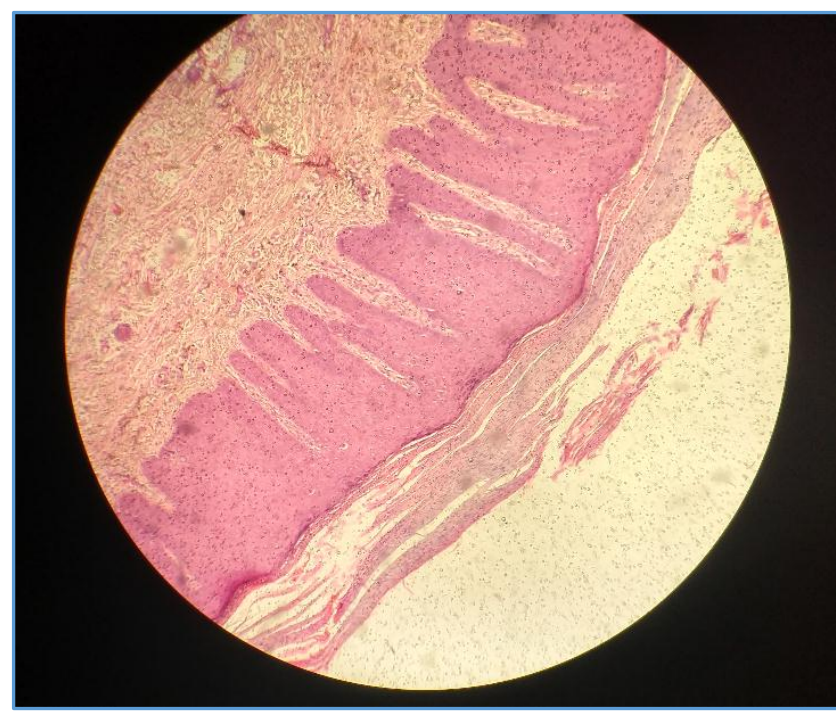

Figure 2. Histopathological Picture of Psoriasis

\section{DISCUSSION}

Though the overall mortality from Psoriasis is minimal, the widely varying morphology of lesions, the unpredictable course and severity increases the morbidity among patients, thus affecting the quality of life. ${ }^{21}$

This study included 82 psoriasis patients, with a male to female ratio of 1.48:1. However Prakash BV et al in their study had a male to female ratio of 3:1, which showed a clear male preponderance, while studies conducted by Na SJ et al and Loo $\mathrm{CH}$ et al had a sex ratio of 1.2:1, almost in line with the data of this study.

$56.1 \%$ of the participants of this study had late onset of psoriasis (Age $>40$ years) and nearly half $(48.8 \%)$ presented with a chronic history of 1-10 years or more. Loo CH et al in 2014 obtained from their study in Malaysia that $54.7 \%$ had early onset disease (age $<40$ years). However, Dogra $S$ et al found out that the peak age of onset in adults is in the $3^{\text {rd } \&} 4^{\text {th }}$ decades of life, which is similar to the results of this study. This similarity may be attributed to similarities in genetic and environmental factors. A study done in Thai population Contrary to this study, stated that $65.2 \%$ had early onset psoriasis and $34.5 \%$ had late onset psoriasis. ${ }^{22}$ The age of onset among males was 20 and teenage among females as per another hospital-based study in Seoul, but no such observation could be made from this study.

The most common variant of psoriasis in this study was chronic plaque psoriasis (36.6\%), followed by nail psoriasis in $19.5 \%$, palmar psoriasis in $2.4 \%$, plantar psoriasis in $9.8 \%$ and pustular psoriasis in $4.9 \%$. Psoriatic arthropathy was seen in $21.9 \%$. Erythrodermic variant was found in only one patient (1.2\%). Chronic plaque psoriasis being the most common variant is agreed in most of the previous studies. No cases of guttate and inverse psoriasis were found in this study. A Malaysian study revealed a higher incidence (89.2\%) of psoriasis vulgaris, others were erythrodermic, pustular and guttate. Chronic plaque psoriasis was found to be the most common variant in a north Indian study with more than 90\% incidence, others were palmoplantar, pustular and recalcitrant. A study by Weigle et al also found that the most common variety was plaque psoriasis, while guttate, pustular and inverse psoriasis were also noted. The study by Hani AF 
et al, also confirmed that the most common morphological variant was plaque psoriasis with red scaly plaques.

According to this study, the most common sites of involvement was the scalp (42.7\%), lower limbs (32.9\%), trunk $(17.1 \%)$ and upper limbs $(7.3 \%)$ in concordance with Burfield L et al. While according to a hospital based Indian study the most common site of involvement was the palms. Psoriatic lesions affecting the scalp, nails, palms and soles were described as difficult to treat according to another study. ${ }^{23}$

Nail involvement was present in only $28 \%$ participants while a much higher incidence of nail involvement was observed by Choi J W et al in 2016 (85.5\%) with 55.6\% having pitting. Loo $\mathrm{C} \mathrm{H}$ et al observed $28 \%$ nail involvement and Na SJ et al observed nail involvement in $26.4 \%$ subjects which are comparable with this study.

Joint involvement was present in $22 \%$ of the patients while a study by Dogra S et al in 2016 stated that there is significant risk of psoriatic arthritis in patients with plaque type psoriasis. Loo $\mathrm{CH}$ et al observed $14.7 \%$ patients with psoriatic arthritis while Choon SE et al found $34.7 \%$ joint involvement in their retrospective study done in 2014. A study by Kumar $\mathrm{R}$ et al found that of $8.7 \%$ patient with psoriatic arthritis $58 \%$ had symmetrical polyarthritis. According to a study by Reich A et al in 2014, the prevalence of psoriatic arthritis is $5-30 \%$.

More than half of the patients (56.1\%) presented with mild psoriasis (PASI $<7$ ) and $22 \%$ each presented with moderate and severe psoriasis. Loo $\mathrm{CH}$ et al in their study calculated that $41.7 \%$ patients had more than $10 \%$ body surface area involvement. Moderate to severe extent of involvement was observed in male patients with early onset psoriasis (Age $<30$ years). A study involving 127 psoriasis patients calculated the severity to be mild in $63 \%$ patients, almost similar to this study. PASI score was higher in those with scalp and nail involvement. ${ }^{24}$ Aarti SS et al stated that $11.6 \%$ in their study presented with mild psoriasis, $44.2 \%$ each presented with moderate and severe types. The comparatively low percentages of severe forms of psoriasis in this study setting may be because it is an OP-based study.

This study was not able to find out a statistically significant association between severity and smoking or alcohol. But the mean PASI score of smokers were higher than that of non-smokers, while there was no association between severity and alcohol consumption according to the study conducted by Asokan $\mathrm{N}$ et al.

The study did not derive any significant relation between severity and duration of disease. Contrary to this, a positive correlation between severity \& duration of disease as well as psychological variants (Depression, anxiety, stress) was established in a case control study 20.

$26.8 \%$ partakers of this study had no aggravating factors while $30.5 \%$ had summer exacerbations, $12.1 \%$ had diet, $9.8 \%$ had trauma as aggravating the disease. Multiple aggravating factors which included smoking, alcohol intake and drugs along with the above factors were identified in $25.6 \%$. No significant history of infections and HIV were recorded. Similar factors were associated with psoriasis as per a study conducted among the Caucasian population though infections and endocrine factors were also found to be aggravating factors by them. ${ }^{25}$ Choon SE et al in their study observed that the common triggers were systemic steroids
(44\%), pregnancy (16.6\%), and URTI (15.6\%), which is quite deviating from the results of this study. In another study from Malaysia, sunlight (46\%), stress (31.1\%), trauma (5.4\%), food (4\%), pregnancy (4\%) and URTI $(2.4 \%)$ were found to be the aggravating factors which is in line with this study though the contribution of stress and URTI was more.

A positive family history was obtained in $17.1 \%$ subjects. $\mathrm{Na}$ SJ et and Choon SE et al obtained a higher positive family history than this study (26\%) and 29\% respectively. Malaysian study by Loo $\mathrm{CH}$ et al had a positive family history in $8.8 \%$ of subjects.

\section{CONCLUSION}

This descriptive study on the clinical manifestations and severity of psoriasis revealed certain significant findings. In this study setting, psoriasis is found to be more common in males and had late onset psoriasis. Aggravating factors vary widely among individuals. People with positive past history and/or family history especially have to be cautious regarding exposure to extremes of temperature, trauma, diet, smoking, alcohol, in order to prevent a possible exacerbation.

The most common variant was the chronic plaque psoriasis, while more than half of the subjects are at the mild stage of the disease with a PASI $<7$. Hence early diagnosis and treatment can effectively slow down the disease progression to severe forms. Involvement of difficult-to-treat sites like scalp, palms, soles and nails need to be dealt with seriously.

However, PASI was insufficient to assess the severity in case of pustular and palmoplantar psoriasis. Here other tools like DLQI need to used, as there is significant reduction in the quality of life inspite of localized involvement.

Severity was found to be more in generalized lesions with ill-defined borders with joint involvement. But association of severity with other variables like age of onset, duration of disease, smoking, alcoholism etc. were found to be insignificant as obtained from this study. More case control studies are needed to accurately relate severity with other variables. Preferably further studies with larger sample sizes are needed so that limitations in the hospital setting may be avoided.

\section{REFERENCES}

[1] Hani AF, Prakasa E, Nugroho H, et al. Body surface area measurement and soft clustering for PASI area assessment. Conf Proc IEEE Eng Med Biol Soc 2012;2012:4398-401.

[2] Mazlin MB, Chang CC, Baba R. Co-morbidities associated with psoriasis - data from the Malaysian psoriasis registry. Med J Malaysia 2012;67(5):518-21.

[3] Choon SE, Lai NM, Mohammad NA, et al. Clinical profile, morbidity and outcome of adult-onset generalized pustular psoriasis: analysis of 102 cases seen in tertiary hospital in Johor, Malaysia. Int J Dermatol 2014;53(6):676-84.

[4] Singh S, Young P, Armstrong AW. Relationship between psoriasis and metabolic syndrome: a systemic review. G Ital Dermatol Venerol 2016;151(6):663-77. 
[5] Kothiwala SK, Khanna N, Tandon N, et al. Prevalence of metabolic syndrome and cardiovascular changes in patients with chronic plaque psoriasis and their correlation with disease severity: a hospital based cross-sectional study. Indian J Dermatol Venereol Leprol 2016;82(5):510-8.

[6] Loo $\mathrm{CH}$, Chan $\mathrm{YC}$, Lee $\mathrm{KQ}$, et al. Clinical profile, morbidity and outcome of adult patients with psoriasis at a district hospital in Northern Malaysia. Med J Malaysia 2015;70(3):177-81.

[7] Asokan N, Prathap P, Rejani PP. Severity of psoriasis among adult males is associated with smoking, not with alcohol use. Indian J Dermatol 2014;59(3):23740.

[8] Reich A, Szepietowski JC. Clinical aspects of itch: psoriasis. Chapter - 4. In: Carstens E, Akiyama T, eds. Itch: mechanisms and treatment. Boca Raton, Florida, USA: CRC Press/ Taylor \& Francis, Frontiers in Neuroscience 2014.

[9] Weigle N, McBane S. Psoriasis. Am Fam Physician 2013;87(9):626-33.

[10] Burfield L, Burden AD. Psoriasis. J R Coll Physicians Edinb 2013;43(4):334-8, quiz 339.

[11] Kumar S, Nayak CS, Padhi T, et al. Epidemiological pattern of psoriasis, vitiligo and atopic dermatitis in India: hospital-based point prevalence. Indian Dermatol Online J 2014;5(Suppl 1):S6-S8.

[12] Choi JW, Kim BR, Seo E, et al. Identification of nail features associated with psoriasis severity. J Dermatol 2017;44(2):147-53.

[13] Fitzgerald 0, Winchester R. Psoriatic arthritis: from pathogenesis to therapy. Arthritis Res Ther 2009;11(1):214.

[14] Kumar R, Sharma A, Dogra S. Prevalence and clinical patterns of psoriatic arthritis in Indian patients with psoriasis. Indian J Dermatol Venereol Leprol 2014;80(1):15-23.

[15] Dogra S, Mahajan R. Psoriasis: epidemiology, clinical features, co-morbidities and clinical scoring. Indian Dermatol Online J 2016;7(6):471-80.
[16] Prakash BV, Sirisha NL, Satyanarayana VV, et al. Aetiopathological and clinical study of erythroderma. J Indian Med Assoc 2009;107(2):100,102-3.

[17] Mattei PL, Corey KC, Kimball AB. Psoriasis Area Severity Index (PASI) and the Dermatology Life Quality Index (DLQI): the correlation between disease severity and disease burden in patients treated with biological therapies. J Eur Acad Dermatol Venereol 2014;28(3):333-7.

[18] Llamas-Velasco $M$, de la Cueva P, Notario J, et al. Moderate psoriasis: a proposed definition. Actas Dermosifiliogr 2017;108(10):911-7.

[19] Lakshmy S, Balasundaram S, Sarkar S, et al. A cross sectional study of prevalence and implications of depression and anxiety in psoriasis. Indian J Psychol Med 2015;37(4):434-40.

[20] Singh SM, Narang T, Dogra S, et al. Screening for depressive disorders in outpatients with mild to moderate psoriasis: a study from North India. Indian J Dermatol Venereol Leprol 2015;81(2):148-50.

[21] Salunke AS, Nagargoje MV, Belgaumkar VA, et al. Association of metabolic syndrome in chronic plaque psoriasis patients and their correlation with disease severity, duration and age: a case control study from Western Maharashtra. J Clin Diagn Res 2017;11(8):WC06-WC10.

[22] Chularojanamontri L, Kulthanan K, Suthipinittharm P, et al. Clinical differences between early- and lateonset psoriasis in Thai patients. Int J Dermatol 2015;54(3):290-4.

[23] Sanchez-Regana M, Soto AMJ, Romoro BI, et al. Evidence-based guidelines of the Spanish psoriasis group on the use of biological therapy in patients with psoriasis in difficult-to-treat sites (nails, scalp, palms and soles). Actas Dermosifiliogr 2014;105(10):923-34.

[24] Çakmur H, Derviş E. The relationship between quality of life and the severity of psoriasis in Turkey. Eur J Dermatol 2015;25(2):169-76.

[25] De la Brassinne M, Failla V, Nikkels A. Psoriasis: state of the art 2013. Acta Clin Belg 2013;68(6):427-32. 